\title{
Marine Protected Areas in Peninsular Malaysia: Shifting from Political Process to Co-Management
}

\author{
Mohd Ashraf Abdul Rahman ${ }^{1}$, Farahdilah Ghazali ${ }^{1}$, Mohd Hazmi Mohd Rusli ${ }^{2}$, Nazli Aziz ${ }^{3}$ \& Wan Izatul Asma \\ Wan Talaat ${ }^{1}$ \\ ${ }^{1}$ Institute of Oceanography and Environment, Universiti Malaysia Terengganu, Malaysia \\ ${ }^{2}$ Faculty of Shariah and Law, Universiti Sains Islam Malaysia, Malaysia \\ ${ }^{3}$ School of Economic and Social Development, Universiti Malaysia Terengganu, Malaysia \\ Correspondence: Farahdilah Ghazali, Institute of Oceanography and Environment, Universiti Malaysia \\ Terengganu, Malaysia. Tel: 601-7907-8601. E-mail: farahdilah.g@umt.edu.my
}

Received: September 3, 2019

doi:10.5539/jpl.v12n4p22
Accepted: September 26, 2019 Online Published: November 28, 2019

URL: https://doi.org/10.5539/jpl.v12n4p22

\begin{abstract}
Since fishing is a primary source of income to the coastal communities, conservation of marine natural resources is crucial to safeguard its sustainable supply. Therefore, intensive measures should be taken by all the stakeholders - from the authorities to the local fishermen. The precious coral reefs should be protected as important breeding habitat of various commercially valued species of marine resources and. Thus, in carrying out the political process of designating marine protected areas (MPAs) as marine parks, the local communities must also be engaged by the government due to their proximity to and dependency on the environment as direct resources users. Co-management or collaborative management by engaging the local communities, or community-based management, is the concept that could be able to remedy ineffective MPAs management in Peninsular Malaysia. Co-management or collaborative management approach between the authorities and the communities must be strategised by factoring in their local knowledge of living within and off the marine environment and resources. This study utilises content analysis method on the primary data, namely the national policies, federal acts, and state enactments. While the secondary data in form of official reports, scholarly articles and others deemed relevant are used to supplement and support the findings. This paper dwells on the possibility of shifting the process of MPAs designation from political process to co-management in Peninsular Malaysia, in order to achieve both environmental stability and the livelihood sustainability of the local communities.
\end{abstract}

Keywords: marine protected areas, political process, co-management, local communities

\section{Introduction}

Seafood security is vital not only for the market but those in the fishing industries. Taking into consideration that fishing is a major source of income to the coastal communities, conservation of marine natural resources is crucial to safeguard its sustainable supply. Intensive measures should be taken by all the stakeholders - from the authorities to the local fishermen. The precious coral reefs are important for many different reasons including as breeding habitat of various commercially valued species of marine resources and should be protected. Intergovernmental oganisations (IGOs) under the United Nations such as the United Nations Environment Programme World Conservation Monitoring Centre (UNEP-WCMC) and the international NGOs like the International Union for Conservation of Nature (IUCN), through its World Commission on Protected Areas, have repeatedly called for the increase the coverage of protected areas globally (UNEP-WCMC, 2016).

The emerging issues of climate change and expansion on human activities have been causing serious impacts to the Earth and its support systems. By means as a tool to protect biodiversity and secure ecosystem services, marine-protected areas (MPAs) limit human activities, particularly fishing activities (Richmond \& Kotowicz, 2015). Before 1972, MPAs were established by local's accord established with the absence of a legal structure. However, with the existing legal framework, MPA governance can be either top-down (centralised) or bottom-up (decentralised). Top-down MPA is the standard method in MPA designation being commonly practised through a political process in Peninsular Malaysia. The Division of Marine Park (formerly the Department of Marine Park) of the Fisheries Department Malaysia was established to manage the existing 42 marine parks gazetted under 
Part IX of the Fisheries Act 1985.

Following the institutional changes theories by de Morais et al., (2015), the arangement of maritime custodian agencies aforementioned made by the Malaysian government could positively influence various biodiversity conservation efforts, fisheries management and social welfare, as well as the global goal on food security of Sustainable Development Goals (SDG) (Tsurita et al., 2018). MPAs are also effective medium to sustain the quality of marine biodiversity as well as in maintaining the ecosystem services and functions. The local communities and the marine ecosystems could benefit from the protected areas, and the resources therein, due to the flow of ecosystem services (Tonin, 2018). MPAs may also benefit in terms of providing resistance against the unpredictable impacts of climate change (Sala \& Giakoumi, 2018). For this study, the content analysis method was employed on two data sources; primary and secondary. The primary data is in the form of national policies, federal acts, and state enactments while the secondary data is retrieved from relevant official reports, scholarly articles, and other sources. As this study is a desktop research, the data gathered are mainly retrieved from the internet.

\section{Why Marine Protected Areas?}

The most stringent form of MPAs is the no-take zone, or also known as a no-take marine reserve, which offers a greater amount of protection to the ecosystems and marine life especially corals (Abesamis et al., 2017). No-take zone has been regarded as the most effective type of MPAs since it restores fish assemblages and ecosystems (Sala \& Giakoumi, 2018). Nevertheless, it must also be borne in mind that successful implementation of MPAs depends greatly on the support of all stakeholders and the acceptance from the local communities (Tonin, 2018). Therefore, designating MPAs without considering the local needs and knowledge may not succeed because the cooperation by the local communities, is crucial to guarantee the success of the MPAs.

There are many definitions of protected areas (PAs) but the widely used definitions are from the Convention on Biological Diversity (CBD) 1992 and the International Union for Conservation of Nature (IUCN). Since the IUCN works have been well recognised and applied in many conventions, it is pertinent to discuss PAs under the organisation. Since all the six categories of PAs designed by IUCN carry certain specifications from 'totally protected' to 'multiple use zones', the revised definition of PAs under IUCN is:-

"A clearly defined geographical space, recognised, dedicated and managed, through legal or other effective means, to achieve the long-term conservation of nature with associated ecosystem services and cultural value".

PAs have been progressively practiced to conserve marine resources. PAs as defined in Article 2 of the CBD refer to "a geographically defined area which is designated or regulated and managed to achieve specific conservation objectives". Nevertheless, Dudley (2008) and Woodley et al. (2011) highlighted the CBD Secretariat approved that their PAs definition brings the same meaning to the newly found definitions by the IUCN. What remains is the true intent of 'protected areas' that CBD carries. Therefore, with the increasing numbers of PAs, whether these PAs are being effectively and equitably managed and their effects from such establishment and management remain ambigouis.

In addition, the Aichi Biodiversity Target, which was acceded by the State Parties during the $10^{\text {th }}$ Conference of Parties (COP-10) in Nagoya, was deposited to further clarify marine protection. Target 11 of Aichi Targets serves a more detailed measurement and time-frame to reinforce the MPA framework, as below:

"By 2020, at least 17 per cent of terrestrial and inland water, and 10 per cent of coastal and marine areas, especially areas of particular importance for biodiversity and ecosystem services, are conserved through effectively and equitably managed, ecologically representative and well connected systems."

As deliberated earlier, designation of these PAs are considered as a robust approach in protecting biological resources and its environment. Regardless of their effectiveness as a conservation tool, it does cause some adverse impacts on local community. This unresolved issue could eventually rise dispute vis-à-vis the compatibility of two main agenda - environmental and socioeconomic (Oldekop et al., 2016). There are arrays of benefits of MPAs, which are mainly for fishery activities, recreation, watershed protection, ecological processes, education and research, cultural values, income source as well as biodiversity conservation. The classification made by Angulo-Valdés and Hatcher (2010) as well as Vu (2013), who explain the benefits of MPAs into two distinct categories - "for human" and "for nature", could be considered as the most apt categorisation. The classification can further be divided as follows:-

1) Benefits for human: 
The benefit of MPA for humans can be direct and indirect. Both Bohnsack (2003) and Halpern (2003) deduced direct benefits to mean that local users feel more profitable in terms of fishing benefits such as greater fish biomass and abundance. These findings were reiterated by Erisman et al., (2017) by verifying the benefits of MPAs on fisheries sector. On the other hand, indirect benefits arise from people living outside the protected area, from various aspects including tourism, employment, coastal protection, ecosystem restoration, global climate change and policy as well as dispute resolution (Stolton et al., 2015). It has thus been acknoweledged that while the most direct benefit to humans is often related to the extraction and use of natural resources under the above "fisheries management", the indirect benefits are associated with fishery ecology over a longer period of natural resource extraction. (Rodwell, \& Roberts, 2000, Potts, 2014).

\section{2) Benefits for nature:}

The benefits for nature are comparable to the conservation of biodiversity, which influences ecological processes such as the nutrient cycle, climate stability, critical habitat, biodiversity, the food web and ecosystem resilience (Board, 2001, Angulo- Valdés \& Hatcher, 2010). In addition to providing provisions to local community, PAs can provide ecosystem services on a global scale, as long as the spatial magnitude is large (Halpern, 2003). At local level, local communities can mainly benefit from fishing, such as catching larvae, overflowing, abundance, size and variety, as described by both Guidetti et al. (2014) and Harrison et al. (2012). Costello (2014) believes that if a sufficiently large MPA exists around the world, more substantial ecosystem services and benefits can be provided, such as carbon sequestration, complete protection of migratory animals, naval defense, coastal erosion and climate control. This view is supported by Potts et al. (2014), which claim that it is possible to protection of critical marine components and processes such as substrates, coral reefs, sea bottoms, hydrological, geological and evolutionary processes. However, constructing large MPAs should come wtih some precaution since MPA sizes can significantly influence the cost, enforcement and monitoring effort. The risk may nonetheless be negated by applying the appropriate tools, conventional process, and informed decision (Bailey \& Thompson, 2009).

These categorisations of benefits are mutually supportive and interdependent of each other. Potts (2014) has foreseen that the sustainability of fishery benefits for human use are dependable on the stability of marine components (e.g. habitat, sea space) and the processes (e.g. food web dynamics, ecological interactions). The benefits may also be classified into "fisheries management" and "biodiversity conservation" (Chaboud, 2011). Idyllically, as noted earlier by Halpern (2003) and Rice et al (2012), the MPAs' objectives are twofold, but a well-designed and executed MPA can balance both fisheries management objectives and biodiversity conservation. To strengthen MPAs and to achieve a balance between these two primary goals, the roles of local community as stakeholders should not be disregraded. The collegiality between conservation and socioeconomic goals can be achieved through management strategies and likely to maximize the outcomes of MPAs establishment (Oldekop et al., 2016).

\section{Designation and Management of Marine Parks in Peninsular Malaysia}

The Federal Constitution of Malaysia has divided the jurisdictions between the federal and state governments, as listed under the Ninth Schedule. Table 1.1 below describes the distribution of powers between federal and states, as provided under the Federal Constitution. This distribution of powers is only applicable to the Peninsular Malaysia, which gained her independence from the British as Malaya in 1957.

Table 1. Distribution of powers in the federal constitution

\begin{tabular}{lll}
\hline \multicolumn{1}{c}{ Federal List } & State List & \multicolumn{1}{c}{ Concurrent List } \\
\hline Mineral resources & Land & Wildlife \\
Marine and estuarine fisheries & Agriculture & Town and country planning \\
Pest control & Forestry & National parks \\
Shipping and navigation & Infrastructure activities for state works & Rehabilitation \\
Water supplies & Water & Eroded and mined land \\
Tourism & Riverine fisheries & Drainage \\
Infrastructure activities for federal works & & Irrigation \\
& & Housing \\
\hline
\end{tabular}

Source: Adopted from the Ninth Schedule of the Federal Constitution 
The federal government is empowered to regulate all matters relating to marine and estuarine fisheries whereas the state governments' jurisdictions are over all land matters including the foreshore and riverine fisheries. Due to the depleting marine fisheries resources and degradation of coral reefs, which were induced by an endless list of issues such as overfishing, prohibited fishing methods, pollutions and sedimentation, the Fisheries (Prohibited Area) Regulations was enacted under the then Fisheries Act 1963, which was a federal law. Pulau Redang in Terengganu became the first fisheries protected area (FPA) (Talaat, Tahir, \& Husain, 2013), which was subsequently converted into a marine park island when the Fisheries Act was amended in 1985. The remaining FPA are Pulau Besar, Tanjung Tuan Melaka, Tanjung Tuan 1, Tanjung Tuan 2, Pulau Talang-Talang Besar dan Pulau Talang-Talang Kecil.

The Fisheries Act 1985, particularly Section 41 to Section 45 under Part IX authorised for the establishment of marine parks in Malaysia. By virtue of the divisions of powers under the Federal Constitution, these existing marine parks fall under the federal jurisdictions and are formally institutionalised under the Marine Parks Division under the Department of Fisheries Malaysia, which is a federal agency (previously before the General Election-14 in May 2018, the division was formerly the Department of Marine Parks). Designation of marine parks through this political process in Malaysia serves to protect, conserve and manage the biological diversity of marine areas inclusive of endangered and threatened species as well as their natural habitats. At present, there are 42 marine park islands gazetted in the the Peninsular Malaysia, which only covers the areas surrounding these designated islands up to 2 nautical miles from the baseline, with the exception to Kapas Island, which is only up to 1 nautical mile from the island's baseline. These MPAs are essential to overcome overexploitation of marine resources and to encourage sustainable fishing.

Although the main aims of designating MPAs under the Fisheries act 1985 are to preserve a specific habitat and to ensure the marine ecosystem is sustained, the Act 1985 allows these MPAs for recreational, as well as for research and educational use. Thus, although in the MPAs, preservation of the health of the marine ecosystem is given the utmost priority, it is irrefutable that the eco-tourism activities allowed within or near the protected areas have been causing serious environmental degradations to the MPAs in Peninsular Malaysia. Coral bleaching and broken corals due to trampling are typical occurrences in these marine park islands.

Furthermore, despite one of the objectives behind the designation of MPAs is to increase the local community's economy by conserving fish biological cycle, some local fishermen are still struggling. Islam et al. (2017) reveal that the no-take area has caused hardship to the local communities' livelihoods as they heavily depend on fishing activities. The detrimental impacts on the livelihood of these fishermen, which were not taken into consideration by the policymakers, has inexorably encumbered the enforcement of MPAs regulations. Pursuant to that, effective enforcement of MPAs regulations by the then Marine Park Department and related agencies could have been undermined through overselling of tourism activities or mass tourism, which has inadvertently caused adverse impacts on the coral reef and other marine life (Islam et al., 2017). The marine parks areas are being managed by a federal agency i.e. the Marine Parks Division of the Malaysian Department of Fisheries while the management of the terrestrial parts of these islands falls under the local governments, which recieve budget from their respective state governments. Sadly, there is an absence of any formal involvement of the local communities in the management of these marine parks, indicating the lack of local community engagement in marine conservation efforts.

\section{Shifting from Political Process to Co-Management in MPA Designation and Management}

Co-management or collaborative management by engaging the local communities, or community-based management, is the concept that could be able to remedy ineffective MPAs management in Peninsular Malaysia. As mentioned above, the establishment of no-take zones would limit access to marine resources and would likely force the local fishermen to commit illegal fishing within and beyond the water boundary. This would exacerbate since the local and indigenous communities were seldom consulted prior to the management decision-making on the establishment of such zoning (Stacey et al., 2017). A previous study in the Wet Tropics of Queensland, Australia has shown successful cooperation between the authorities and the local community whereby the locals were allowed to use knowledge to resolve species management issues (Hill, Baird, \& Buchanan, 1999). There has also been inclining numbers of governing frameworks to promote the rights of the local communities, including the indigenous, to access the natural resources, and to engage them in management of conservation areas as well as to compensate their loss due to imposing restrictions, such as no-take area (Stacey et al., 2017). This shows the importance of the local community engagement in the management and decision-making process and the role of good governance to assist the management of MPAs (Pomeroy, Lani, John, \& Gonzalo, 2005).

The basis of community-based MPAs is to converge the craftsmanship of fisheries management and biodiversity 
conservation (Christie \& White, 2006). Bottom-up or community-based approaches are prevalent in some jurisdictions whereby the institutional frameworks are irresolutely resulting from colonialism or ineffective government, or simply because of financial and technical resources constraints. Even so, some factors may contribute to effective community-based management of MPAs on account of active participation of resource users and because of this, a sense of ownership, trust, and collaboration may build up (Pollnac \& Pomeroy, 2005; Christie \& White, 1997).

As noted above, it has also been already proven that the formal marine conservation efforts via MPAs designation have led to adverse impacts to the indigenous semi-migratory and nomadic peoples since such reserves impose restrictions to access marine resources. Nevertheless, their participation and engagement in the conservation programmes would assist these communities in designing programmes to safeguard the sustainable use of marine resources (Stacey, Acciaioli, Clifton, \& Steenbergen, 2017).

Following the above discussion, since these MPAs are also designated as tourist destination islands, it may not be wrong to infer that this top-down decision was made without considerations on the resource users' (in this case the local fishermen) knowledge, perception and understanding of their surrounding marine environment. The local communities may have not been consulted from the beginning during the MPA designation process. Being a country that has been considered to have good governance and is financially stable, community-based MPAs is almost absent in this country, as opposed to neighbouring Thailand, the Philippines, and Indonesia, where the local communities play integral and essential roles in managing their marine environment.

The effectiveness of an MPA management is judged based on several indicators such as levels of local participation or engagement in the decision-making process and the assessment on the impacts on local community livelihoods (McClanahan, Marnane, Cinner, \& Kiene, 2006). It is also crucial to know whether the local community has motivations to participate in resource management (Jones, Qiu, \& Santo, 2013) because this will lead the directions in policy and decision making. As noted by Cinner (2005), several studies have already emphasised the importance of local engagement to navigate the successful implementation of MPAs management.

There are several social challenges to be encountered in order to include the local community in MPA management, such as bureaucracy that includes top management authority to make the final decisions (Stephenson, Berkes, Turner, \& Dick, 2014). Nonetheless, it is also irrefutable that engaging the local and indigenous community in the decision-making process of an MPA governance and management is crucial to protect and conserve marine biodiversity and resources. One good example of the role of community in the collaborative governance for the establishment of MPAs ands resource management is well reflected in the case of the Haida Nation where it was incorporated for the purposes of marine conservation and sustainable use of marine resources (Gaymer et al., 2014). However, a study by Chaigneua and Daw (2015) showed that most community support for MPAs were assessed at village or community level rather than individual. They suggested that individual differences should be considered as criteria in developing a community-based conservation programme to attract more public participation.

A number of large scale MPAs in the Pacific like the Phoenix Islands Protected Area, the Pacific Remote Islands Marine National Monument, the Motu Motiru Hiva Marine Park, the Natural Park of the Coral Sea, have established successful collaborations whereby their cooperations inclusieve of bilateral agreements, research, monitoring and enforcement to manage maritime jurisdictional territories and their resources (Friedlander et al., 2016). Through collaboration process, which involved resources and information sharing and knowledge exchange, the sustainability of marine resources could be achieved. Gaymer et al. (2014) in their study have highlited the challenges to reach the balance between top-down and bottom-up processes, which is better known as community-based approach. This has indicated that despite the many studies suggesting on the importannce to engage the local communities, political will is still necessary to engage these communities.

Traditional Ecological Knowledge (TEK) of the local communities is used to sustain the community and its culture, and to maintain the biological resources necessary for the continued survival of the community (Hansen, 2002). Leopold, Herrenschmidtb, \& Thamanc (2008) define marine TEK as part of the larger body of indigenous knowledge to include a complex knowledge of the sea (i.e. reefs, lagoons, and target species), the livelihood activities (fishing techniques and practices, management rules), and the related beliefs and legends of social and cultural values. Therefore, the information and knowledge of the local fishermen as direct users has been helping many conservation efforts with their knowledge on the presence, abundance and threats of marine lives, which have become the starting points for most scientific researches to understand more and tackle the problems efficiently (Rajamani, Rodriquez-Vaga, \& Oii, 2014). 
Martin et al. (2007) believed that an ecosystem and community-based approach will assist local communities to conserve marine environment and resources. Thus, it is crucial to engage the local fishermen and communities in protecting the marine environment, starting from when the MPA designation process commences to the joint-management of the MPA. This stand is supported by Setiati, Peniati, \& Partaya (2018) because the local communities are the ones being directly impacted by the volatility of supply in fishery and other marine resources. Taking into consideration of their livelihood dependency on the marine environment and resources as direct users has been helping many conservation efforts. Their knowledge on the presence, abundance and threats of marine lives have in fact become the baseline information for most scientific researches to overcome threats to the marine environment.

One best example of the effectivenss of co-management by including local participation has been well reflected on the island of Kaledupa, Indonesia, whereby the no-take zone was managed by the Bajau community (Clifton, 2003). Moreover, this adaptive co-management strategy has also closed the gap between the scientists and the local communities, particularly fishers and subsequently overcome problems relating to overfishing. This co-management strategy may also improve via catch-share practices, whereby privileges to harvest in certain area, or percentage of catch, will be granted to stakeholders, which theoretically support the sustainable use of fish stock (Guidetti \& Claudet, 2010). Although it has been argued that co-management approach summons for significant investment and is uneconomical especially in isolated areas with limited facilities, Weeks \& Jupiter (2013) has rebutted the argument by reasoning that despite the initial cost for this strategy, this approach will be advantageous in the long run.

\section{Conclusion}

Designating an MPA is a political process made by the government to effectively maintain the natural processes and support systems in the whole marine ecosystem. Marine parks in Malaysia are areas of the sea that has been zoned as sanctuaries for the coral reef community, with the aim to protect the health of the marine environment that includes all marine lives and their habitats. These marine parks are being managed by a federal agency, the Marine Parks Division of the Department of Fisheries Malaysia while the management of the terrestrial parts of these islands falls under the local governments. Sadly, there is an absence of any formal involvement of the local communities in the management of these marine parks, indicating the lack of local community engagement in marine conservation efforts.

In other countries, co-management has long been recognized as a medium to describe joint management arrangements between the government and the local community. Although local fishermen have limited scientific knowledge and TEK is attained informally through long experiences, it has already been recognised that this knowledge facilitates scientific research by providing baseline information. Since TEK has now been proven globally as promoting the sustainable use of the marine environment and resources, acknowledging the TEK along with the local communities' interests will assist in achieving effective management of the fishery or marine resources.

Collaborative management with the community's participation or community-based management would eventually help develop interests and commitment to work together with the relevant government agencies to manage as well as conserve the marine environment and resources in a sustainable manner. This approach may be able to help safeguard the effectiveness of the MPAs. It goes without saying that engaging the local communities as direct users of the marine resources could create a sense of belonging and responsibilities, which would assist not only in the effective management of the MPAs, but from the early stage of designating such MPAs as well.

\section{Acknowledgments}

The authors wish to acknowledge the Malaysian Ministry of Education for the funding under the Higher Institution Centre of Excellence Grant number 66928.

\section{References}

Abesamis, R. A., Saenz-Agudelo, P., Berumen, M. L., Bode, M., Jadloc, C. R. L., Solera, L. A., ... Russ, G. R. (2017). Reef-fish larval dispersal patterns validate no-take marine reserve network connectivity that links human communities. Coral Reefs, 36(3), 791-801. https://doi.org/10.1007/s00338-017-1570-0

Bailey, H., \& Thompson, P. M. (2009). Using marine mammal habitat modelling to identify priority conservation zones within a marine protected area. Marine Ecology Progress Series, 378, 279-287. https://doi.org/10.3354/meps07887

Berkes, F. (1993). Traditional Ecological Knowledge in Perspective. In J.T. Inglis (Ed.), Traditional Ecological 
Knowledge: Concepts and Case.

Chaigneau, T., \& Daw, T. M. (2015). Individual and village-level effects on community support for Marine Protected Areas (MPAs) in the Philippines. Marine Policy, 51, 499-506. https://doi.org/10.1016/j.marpol.2014.08.007

Christie, P., \& White, A. T. (1997). Trends in Development of Coastal Area Management in Tropical Countries: From Central to Community Orientation. Coastal Management, 25(2), 155-181. https://doi.org/10.1080/08920759709362316

Cinner, J., (2005). Socioeconomic factors influencing customary marine tenure in the Indo-Pacific. Ecological Society, 10(1), 1-14. https://doi.org/10.5751/ES-01364-100136

Clifton, J. (2003). Prospects for co-management in Indonesia's marine protected areas. Marine Policy, 27(5), 389-395. https://doi.org/10.1016/S0308-597X(03)00026-5

de Morais, G. W., Schlüter, A., \& Verweij, M. (2015). Can institutional change theories contribute to the understanding of marine protected areas?. Global Environmental Change, 31, 154-162. https://doi.org/10.1016/j.gloenvcha.2015.01.008

Dudley, N. (2008). IUCN Guidelines for applying protected area management categories. Gland, Switzerland: IUCN. www.iucn.org/about/work/programmes/gpap_home/gpap_capacity2/gpap_pub/gpap_catpub

Erisman, B., Heyman, W., Kobara, S., Ezer, T., Pittman, S., Aburto - Oropeza, O., \& Nemeth, R. S. (2017). Fish spawning aggregations: where well - placed management actions can yield big benefits for fisheries and conservation. Fish and Fisheries, 18(1), 128-144. https://doi.org/10.1111/faf.12132

Friedlander, A. M., Wagner, D., Gaymer, C. F., Wilhelm, T. A., Lewis, N. A., Brooke, S., ... Varmer, O. (2016). Co - operation between large - scale MPAs: successful experiences from the Pacific Ocean. Aquatic Conservation: Marine and Freshwater Ecosystems, 26, 126-141. https://doi.org/10.1002/aqc.2645

Gaymer, C. F., Stadel, A. V., Ban, N. C., Cárcamo, P. F., Ierna Jr, J., \& Lieberknecht, L. M. (2014). Merging top - down and bottom - up approaches in marine protected areas planning: experiences from around the globe. Aquatic Conservation: Marine and Freshwater Ecosystems, 24(S2), 128-144. https://doi.org/10.1002/aqc.2508

Guidetti, P., \& Claudet, J. (2010). Comanagement practices enhance fisheries in marine protected areas. Conservation Biology, 24(1), 312-318. https://doi.org/10.1111/j.1523-1739.2009.01358.x

Hansen, S. A. (2002). Intellectual Property and Traditional Ecological Knowledge: Institutionally Globalized Biopiracy? Professional Ethics Report, XV(3), 1-4.

Hill, R., Baird, A., \& Buchanan, D. (1999). Aborigines and fire in the Wet Tropics of Queensland, Australia: Ecosystem management across cultures. Society \& Natural Resources, 12(3), 205-223. https://doi.org/10.1080/089419299279704

Hind, E. J. (2015). A review of the past, the present, and the future of fishers' knowledge research: a challenge to established fisheries science. ICES Journal of Marine Science, 72, 341-358. https://doi.org/10.1093/icesjms/fsu169

Hiwasaki, L., Luna, E., Syamsidik, \& Shaw, R. (2014). Process for Integrating Local and Indigenous Knowledge with Science for Hydro-Meteorological Disaster Risk Reduction and Climate Change Adaptation in Coastal and Small Island Communities. International Journal of Disaster Risk Reduction, 10(Pt. A), 15-27. https://doi.org/10.1016/j.ijdrr.2014.07.007

Islam, G. M. N., Tai, S. Y., Kusairi, M. N., Ahmad, S., Aswani, F. M. N., Senan, M. K. A. M., \& Ahmad, A. (2017). Community perspectives of governance for effective management of marine protected areas in Malaysia. Ocean \& Coastal Management, 135, 34-42. https://doi.org/10.1016/j.ocecoaman.2016.11.001

Jones, P. J. S., Qiu, W., \& Santo, E. M. D. (2013). Governing marine protected areas: Social ecological resilience through institutional diversity. Marine Policy, 41, 5-13. https://doi.org/10.1016/j.marpol.2012.12.026

Leopold, M., Herrenschmidtb, J. B., \& Thamanc, R. (2008). The Relevance of Traditional Ecological Knowledge for Modern Management of Coral Reef Fisheries in Melanesia. In Proceedings of the 11th International Coral Reef Symposium, Ft. Lauderdale, Florida, 7-11 July.

Malaxi: Terengganu map. Retrieved December 30, 2018, from 
http://www.malaxi.com/terengganu/terengganu_map.html

Martin, K. S., McCay, B. J., Murray, G. D., Johnson, T. R., \& Oles, B. (2007). Communities, knowledge and fisheries of the future. International Journal of Global Environmental Issues, 7(2-3), 221-239. https://doi.org/10.1504/IJGENVI.2007.013575

McClanahan, T. R., Marnane, M. J., Cinner, J. E., \& Kiene, W. E. (2006). A comparison of marine protected areas and alternative approaches to coral-reef management. Current Biology, 16(14), 1408-1413. https://doi.org/10.1016/j.cub.2006.05.062

Mizuta, D. D., \& Vlachopoulou, E. I. (2017). Satoumi concept illustrated by sustainable bottom-up initiatives of Japanese Fisheries Cooperative Associations. Marine Policy, 78, 143-149. https://doi.org/10.1016/j.marpol.2017.01.020

Oldekop, J. A., Holmes, G., Harris, W. E., \& Evans, K. L. (2016). A global assessment of the social and conservation outcomes of protected areas. Conservation Biology, 30(1), 133-141. https://doi.org/10.1111/cobi.12568

Pollnac, R., \& Pomeroy, R. S. (2005). Factors Affecting the Long-term Sustainability of Integrated Coastal Management Projects in the Philippines and Indonesia. Ocean and Coastal Management, 48(3-6), 33-51. https://doi.org/10.1016/j.ocecoaman.2005.04.003

Pomeroy, R., Lani, M. W., John, E. P., \& Gonzalo, A. C. (2005). How is your MPA doing? A methodology for evaluating the management effectiveness of marine protected areas. Ocean Coastal Management, 48(7-8), 485-502. https://doi.org/10.1016/j.ocecoaman.2005.05.004

Rajamani, L., Rodriquez-Vaga, L. H., \& Oii, S. L. (2014). Local Community Knowledge of Penang's Marine Mammals. In E. Norizan, L. Rajamani \& M. Y. Zuraidah (Eds.), Reengineering Local Knowledge: Life, Science and Technology (pp. 73-89). Pulau Pinang: Penerbit USM.

Richmond, L., \& Kotowicz, D. (2015). Equity and access in marine protected areas: The history and future of 'traditional indigenous fishing'in the Marianas Trench Marine National Monument. Applied Geography, 59, 117-124. https://doi.org/10.1016/j.apgeog.2014.11.007

Sala, E., \& Giakoumi, S. (2018). No-take marine reserves are the most effective protected areas in the ocean. ICES Journal of Marine Science, 75(3), 1166-1168. https://doi.org/10.1093/icesjms/fsx059

Setiati, N., Peniati, E., \& Partaya. (2018). Diversity and Conservation Knowledge of Chondrichthyans in Northern Coastal Areas of Central Java. Biosaintifika: Journal of Biology \& Biology Education, 10(2), 471-476. https://doi.org/10.15294/biosaintifika.v10i2.15341

Stacey, N., Acciaioli, G., Clifton, J., \& Steenbergen, D. J. (2017). Impacts of marine protected areas on livelihoods and food security of the Bajau as an indigenous migratory people in maritime Southeast Asia. In L. Westlund, A. Charles, S. M. Garcia, \& J. Sanders (Eds.), Marine protected areas: Interactions with fishery livelihoods and food security (pp. 113-126). Rome: Food and Agriculture Organisation of the United Nations. Retrieved from http://www.fao.org/policy-support/resources/resources-details/en/c/853709/

Stephenson, J., Berkes, F., Turner, N. J., \& Dick, J. (2014). Biocultural conservation of marine ecosystems: examples from New Zealand and Canada. Indian Journal of Traditional Knowledge, 13(2), 257-265.

Stephenson, R. L., Paul, S., Pastoors, M. A., Kraan, M., Holm, P., Wiber, M., ... Benson, A. (2016). Integrating fishers' knowledge research in science and management. ICES Journal of Marine Science, 73(6), 1459-1465. https://doi.org/10.1093/icesjms/fsw025

Stolton, S., Dudley, N., Avcioglu Cokcaliskan, B., Hunter, D., Ivanic, K. Z., Kanga, E., ... Wong, M. (2015). Values and benefits of protected areas. ANU Press.

Talaat, W. I. A. W., Tahir, N. M., \& Husain, M. L. (2013). The Laws and Policies for the Sustainable Management of Biodiversity in Malaysia. Journal of Sustainability Science and Management, 8(2), 276-289.

Thornton, T., \& Scheer, A. (2012). Collaborative engagement of local and traditional knowledge and science in marine environments: a review. Ecology and Society, 17(3). https://doi.org/10.5751/ES-04714-170308

Tonin, S. (2018). Citizens' perspectives on marine protected areas as a governance strategy to effectively preserve marine ecosystem services and biodiversity. Ecosystem Services, 34(Pt. B), 189-200. https://doi.org/10.1016/j.ecoser.2018.03.023 
Tourism Malaysia. Malaysia Truly Asia-Diving in Malaysia. (13 July 2010). Retrieved December 30, 2018, from https://blog.tourism.gov.my/diving-in-malaysia/

Tsurita, I., Horib, J., Kuniedac, T., Horid, M., \& Makino, M. (2018). Marine protected areas, Satoumi, and territorial use rights for fisheries: A case study from Hinase, Japan. Marine Policy, 91, 41-48. https://doi.org/10.1016/j.marpol.2018.02.001

Vicziany, M., Chattopadhyay, D., \& Bhattacharyya, S. (2017). Food from sewage: fish from the east Kolkata wetlands and the limits of traditional knowledge. South Asia: Journal of South Asian Studies, 40(3), 619-644. https://doi.org/10.1080/00856401.2017.1341038

Weeks, R., \& Jupiter, S. D. (2013). Adaptive comanagement of a marine protected area network in Fiji. Conservation Biology, 27(6), 1234-1244. https://doi.org/10.1111/cobi.12153

\section{Copyrights}

Copyright for this article is retained by the author(s), with first publication rights granted to the journal.

This is an open-access article distributed under the terms and conditions of the Creative Commons Attribution license (http://creativecommons.org/licenses/by/4.0/). 